\title{
A Review of Hydrothermal Carbonization of Carbohydrates for Carbon Spheres Preparation
}

\author{
Rui $\mathrm{Li}^{1}$ and Abolghasem Shahbazi ${ }^{2, *}$ \\ 1: Joint School of Nanoscience and Nanoengineering, North Carolina A \& T State University, Greensboro, \\ NC, United States \\ 2: Biological Engineering Program, Department of Natural Resources and Environmental Design, North \\ Carolina A \& T State University, 1601 East Market Street, Greensboro, NC 27411, United States
}

Received January 28, 2015; Accepted March 13, 2015; Published March 15, 2015

\begin{abstract}
Carbon spheres have attracted a great deal of attention due to their applications as super capacitors, catalyst supports, and adsorbents. Carbon spheres can be prepared with controlled size and with oxygenated functional groups on the surface by the hydrothermal carbonization. The further processed products have a high surface area and high thermal stability. Among various methods for fabrication of carbon spheres, the hydrothermal carbonization is favored because of its mild operating conditions. In addition, hydrothermal carbonization can synthesize micro or nano scale carbon spheres environmentally friendly without employing organic solvents, surfactants, or catalysts. In this review, we present the effects of process parameters, structural characteristics of carbon spheres, possible formation mechanisms of carbon spheres, and applications in catalysis.
\end{abstract}

Keywords: Hydrothermal Carbonization (HTC); Carbon Spheres; Carbohydrates; Glucose; Process Parameters; HTC Mechanism; Applications of Carbon Spheres

\section{Introduction}

\subsection{Carbon Spheres Preparation and Hydrothermal Carbonization}

Carbon spheres have received growing research attention due to their structure [13], high electrical conductivity [4], and excellent chemical stability [5, 6], which exhibit potential applications in supercapacitors [7, 8], catalyst supports [9], and adsorbents [10]. Various approaches have been used to prepare carbon spheres, such as chemical vapor deposition [11, 12], the templating method [13, 14], pyrolysis of carbon sources [15, 16], and hydrothermal treatment [17]. Among the aforementioned approaches, the hydrothermal treatment method is more favorable because of mild operational conditions [18] and the controllable size of carbon spheres $[19,20]$. Thus, the hydrothermal carbonization method provides an efficient and scalable route to synthesize carbon particles at low pressure and low temperature [21].

Hydrothermal carbonization (HTC) is a thermochemical conversion process carried out under mild operating conditions in a sub-critical water medium [22], while the critical point occurs at $374^{\circ} \mathrm{C}$ and $22.1 \mathrm{MPa}$ in water [23]. During the HTC procedure, the solution of carbohydrate precursors is usually heated to $130-250{ }^{\circ} \mathrm{C}$ under self- 
generated pressures [17]. HTC has several advantages: Firstly, drying wet feedstocks is avoided, which opens up a large variety of feedstocks with a high water content of 75-90 $w t \%$ [24]. Secondly, HTC operates in water at low reaction temperature. Thirdly, the products generally exhibit uniform chemical and structural properties. However, the products have almost no porosity, unless they were synthesized in the presence of a template or subjected to additional heat treatment at a higher temperature [25].

\subsection{History of Hydrothermal Carbonization}

The application of hydrothermal carbonization for carbon formation was first reported by the German chemist Friedrich Bergius, who was awarded the Nobel Prize in 1913 [26]. Over a long period of time, the hydrothermal process was mainly focused on producing aqueous products such as phenol, furan derivatives, and organic acids. So, the residence time of hydrothermal treatment was shortened to prevent further aromatization or polymerization. Because of multiple applications of carbon spherical particles, a renaissance of HTC of carbohydrates to synthesize carbon spheres at a low temperature gradually came back since 2001. Especially, it had attracted the interest of many researchers after 2006, since Dr. Markus Antonietti at the Max Planck Institute of Colloids and Interfaces (Germany) investigated more details of HTC [25].

\subsection{Materials and Methods}

Table 1 summarizes hydrothermal carbonization studies for carbon spheres formation between 2001 and 2014. Until now, simple monosaccharide and oligosaccharides have been effectively employed as HTC starting materials [27]. Extensive studies have been carried out on glucose as a model compound. Spherical carbon particles were prepared through either a direct hydrothermal process or a hydrothermal process followed by a carbonization process [28]. Experiments were carried out in an autoclave partly filled with the precursor solution. The autoclave was heated to a specific temperature for a given period of time. The reaction temperature and pressure were below the critical point of water. The obtained solid products were separated by centrifugation and washed with water and ethanol to remove residual byproducts, like levulinic acid.

Table 1. Hydrothermal carbonization studies for carbon spheres formation in literature.

\begin{tabular}{|c|c|c|c|c|}
\hline Products & Feedstock & $\begin{array}{c}\text { Particle Size } \\
(\mu \mathrm{m})\end{array}$ & HTC Conditions & Reference \\
\hline Carbon nanospheres & Glucose & $0.1-0.2$ & $180^{\circ} \mathrm{C}$ for $4 \mathrm{~h}$ & {$[29]$} \\
\hline Carbon spheres & Glucose & 0.35 & $190^{\circ} \mathrm{C}$ for $4 \mathrm{~h}$ & {$[30]$} \\
\hline $\begin{array}{c}\text { Uniform carbon } \\
\text { microspheres }\end{array}$ & $\begin{array}{c}\text { Glucose, sucrose, } \\
\text { and starch }\end{array}$ & $0.4-6.0$ & 170 to $240^{\circ} \mathrm{C}$ & {$[31]$} \\
\hline Carbon microspheres & Glucose & $1-2$ & $500^{\circ} \mathrm{C}$ for $12 \mathrm{~h}$ & {$[32]$} \\
\hline $\begin{array}{c}\text { Colloidal carbon spheres } \\
\text { Monodispersed hard carbon } \\
\text { spheres }\end{array}$ & Glucose & $0.1-0.2$ & $\begin{array}{c}160^{\circ} \mathrm{C} \text { for } 6 \mathrm{~h} \text { followed } \\
\text { by } 500^{\circ} \mathrm{C} \text { for } 4 \mathrm{~h}\end{array}$ & {$[33]$} \\
\hline Carbon microspheres & Starch & $1-5$ & $190^{\circ} \mathrm{C}$ for $5 \mathrm{~h}$ & {$[28]$} \\
\hline
\end{tabular}




\section{Hydrothermal Carbonization Process}

\subsection{HTC Products of Glucose}

The HTC products of glucose included an insoluble residue consisting of carbonaceous spherical particles, aqueous soluble products, and gaseous products [31]. The process water contained large quantities of aqueous soluble organic compounds [35]. Among them, a remarkable amount of hydroxymethylfurfural (HMF), levulinic acid, dihydroxyacetone, and formic acid were detected [20]. But phenol, phenol derivatives, other acids, and aldehydes were not found [36]. The gas phase consisted about $70-90 \%$ of $\mathrm{CO}_{2}$, which derived from formate via decarboxylation [37]. Other gases were $\mathrm{CO}$ and $\mathrm{H}_{2}$ $[22]$.

Carbon spheres synthesized directly from carbohydrates at low temperatures possessed very low surface areas $\left(<10 \mathrm{~m}^{2} / \mathrm{g}\right)$ with a small volume of micropores, which was common for hydrothermal carbons [38]. Highly disordered carbon spheres from glucose were hydrophilic amorphous carbons $[8,31]$, which had a polymer-like structure consisting of polyfuranic chains [33]. This polymer-like structure was formed through polymerization or aromatization of furan-like molecules [36]. So, the core of carbon spheres was composed of hydrophobic polyfuran compounds [20]. Carbon spheres had carbonyl [27] and carboxylic acid functional groups on the hydrophilic surface [39].

As an efficient way to enhance surface area, heat treatment may remove the functional groups from the surface of HTC carbons, and create some micropores. The surface area of glucose-derived HTC carbons after further heat treatment at $1000^{\circ} \mathrm{C}$ could reach $400 \mathrm{~m}^{2} / \mathrm{g}$ [28]. The morphology of HTC carbons did not change upon further heat treatment. But the surface appeared rougher because of micropore formation. If the heating temperature was too high, carbon spheres linked each other [40].

In terms of the carbon content, HTC of glucose increased the carbon content of colloid carbon spheres from $40 \mathrm{wt} \%$ to above $60 \mathrm{wt} \%$, while the oxygen content was reduced [36]. After the further heat treatment, the carbon content increased from $60 \mathrm{wt} \%$ to above $80 \mathrm{wt} \%$, while oxygen contents were correspondingly reduced [40].

\subsection{Influence of Process Parameters}

The size and the size distribution of colloidal carbon spheres prepared by HTC were influenced by processing temperature [41], reaction time, and the concentration of starting material [42].

\subsubsection{Temperature}

Colloidal carbon spheres were usually generated by HTC of glucose at a temperature of $170-260{ }^{\circ} \mathrm{C}$. The minimum temperature for the hydrothermal carbon formation from glucose was $160^{\circ} \mathrm{C}$, and hydrothermal carbonization did not take place below $160^{\circ} \mathrm{C}$ resulting in almost no solid residues [31]. At $180^{\circ} \mathrm{C}, \mathrm{HTC}$ carbons formed were rich in carbonyl functionalities [41]. Increasing the HTC temperature led to hydrothermal carbons with a higher degree of aromatization, which was the normal tendency for a carbonization process. For example, hydrothermal carbon spheres, which were derived from HTC of $0.5 \mathrm{~mol} / \mathrm{L}$ pure glucose solution for $4.5 \mathrm{~h}$ at different temperatures of $170,180,190,210$, and $230^{\circ} \mathrm{C}$, had diameters of about $0.4,0.44,1.2,1.2$, $1.4 \mu \mathrm{m}$, respectively [31]. Above $280^{\circ} \mathrm{C}$, only a very small fraction of carbon microspheres was generated, because the aliphatic carbon content decreased at temperatures higher than $260^{\circ} \mathrm{C}$ [43]. 
The processing temperature affected both the average diameter of carbonaceous particles and the size distribution. Higher temperature led to uniform particle diameter and a more homogeneous average size [41]. When the temperature was relatively low, glucose decomposed slowly. New nuclei may just form while the former nuclei already started carbonization, resulting in different growing time. So, under lower temperature, the size distribution was wider. When the temperature was relatively high, glucose can decompose completely very fast. All nuclei occurred at the same time, which led to a more homogeneous average size. But if the processing temperature was too high, formed microspheres had a risk to fuse together and become larger.

\subsubsection{Residence Time}

Exact residence time cannot be determined since reaction rates remained largely unknown, but typical published experimental residence time varied between 1 and $72 \mathrm{~h}$ [35]. A longer residence time led to higher reaction severity and less organic loss in the sugar solution. For instance, when HTC experiments were carried out at a constant concentration of $0.5 \mathrm{~mol} / \mathrm{L}$ glucose and $160^{\circ} \mathrm{C}$, as the residence time increased from 2 to $4,6,8$, and $10 \mathrm{~h}$, the diameters grew from 0.2 to $0.5,0.8,1.1$, and $1.5 \mu \mathrm{m}$ [42]. However, if the reaction time was too long, the produced carbon spheres fused, giving rise to particles with irregular shapes [30].

Dr. Titirici described in detail a conventional HTC process with a residence time [25]. When HTC experiments were carried out at a constant concentration of $10 \mathrm{wt} \%$ glucose and $180^{\circ} \mathrm{C}$, during the first $2 \mathrm{~h}$, no solid residues were observed, and glucose was dehydrated and decomposed into small soluble organic molecules. After $4 \mathrm{~h}$, the color of the solution became dark orange suggesting that polymerization and aromatization occurred, called polymerization step. Past $5 \mathrm{~h}$, the first solid precipitated out of the aqueous solution. After $8 \mathrm{~h}$, a brown colloidal dispersion was formed. The black-brown solid formed spherically shaped particles of around $0.5 \mu \mathrm{m}$, aggregated together in $12 \mathrm{~h}$. The growth process kept continuing, and the particle size increased to around $1.5 \mu \mathrm{m}$ until all HMFs have been consumed.

\subsubsection{Precursor Concentration}

The size of carbon spheres increased with the elevated concentration of glucose solution within a certain concentration range [30]. When the concentration of glucose increased from 0.5 to $1 \mathrm{~mol} / \mathrm{L}$, the diameters grew from 1.2 to $1.4 \mu \mathrm{m}$, if HTC experiments were carried out at a constant temperature of $190^{\circ} \mathrm{C}$ and dwell time of $4.5 \mathrm{~h}$ [31]. However, when the concentration reached to a certain degree, the size turned to be constant. For example, at same reaction conditions, when the concentration of sugar

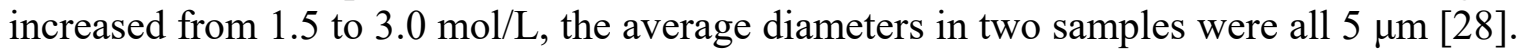
In addition, excessive concentration led to a larger particle size distribution. On one hand, a high concentration of carbon microspheres increased the probability of crosslinking. On the other hand, a higher concentration of glucose needed a longer time to dehydrate completely, which led to different formation time.

\subsubsection{Carbohydrate Precursors}

HTC had a wide range of possible sources such as carbohydrates (glucose, fructose, xylose, sucrose, cellulose, and starch) [31, 34], biomass [35], sewage sludge, animal manure, municipal solid waste [44], agricultural residues, and algae [24]. It's difficult for HTC of biomass to form carbon spheres with regular morphology in a 
uniform chemical structure compared to simple saccharides. For example, hydrothermal carbonization of eucalyptus sawdust or barley straw at $250^{\circ} \mathrm{C}$ formed carbon microspheres with the size of 1-10 $\mu \mathrm{m}$ from cellulose fraction of biomass. But these carbon microspheres covered with particles retained the cellular appearance of raw materials [45]. Therefore, carbon spheres from HTC of biomass were rarely used in catalytic and electrode applications. So far, carbohydrates have been ideal starting materials for preparing carbon spheres, because they were cheap and favored in the dehydration process [46], and products had a uniform chemical structure. All materials obtained from hexoses-based mono- (glucose, HMF), di- (maltose, sucrose), and polysaccharides (amylopectin, starch) can be hydrolyzed to glucose units. Under similar operational conditions, the diameters of carbon microspheres depended on the type of saccharides used. The average diameter of carbon microspheres derived from different carbohydrates had a sequence of sucrose $>$ starch $>$ glucose [31]. This variation was related to the number of decomposed species generated from different saccharides, which were obviously greater in the case of starch and sucrose due to their polysaccharide and disaccharide nature, respectively [31]. Carbonaceous materials derived from pentosebased carbohydrates showed morphological and chemical differences from hexose-based ones [27]. Because furfural was the main dehydration product from pentose-based saccharides, while HMF was the main dehydration product from hexoses-based saccharides [40].

\subsection{5 $\mathrm{pH}$}

The formation of acids was inevitable during the HTC, lowering the $\mathrm{pH}$ value to $\sim 3$ [31]. This acidic condition tended to increase the reaction rate in HTC, because the hydronium ions generated from these acids catalyzed dehydration and further polymerization of HMF [25]. A pH of 1.5 solution could increase glucose destruction [47]. The addition of acid in the fructose solution caused high yields of HMF and furfural, and decreased yields of pyruvaldehyde and lactic acid [48].

\subsubsection{Pressure}

Pressure had no significant effect on promoting HTC conversion, because the HTC reaction occurred in the liquid phase. The resulting pressure in a close compartment was higher than the saturated vapor pressure due to the formation of gases.

\subsection{Possible HTC Mechanism of Glucose and Cellulose}

The possible mechanism is schematically illustrated in Fig. 1. When glucose was dissolved in water, it existed in three forms: an open chain, a pyranose ring, and a furanose ring [49]. The levoglucosan (1, 6-anhydro- $\beta$-D-glucopyranose) was produced by the dehydration of glucose. Erythrose and glycolaldehyde were transformed from glucose by retro-aldol condensation [50]. Glyceraldehyde was transformed from fructose, isomerization of glucose, by retro-aldol condensation [51]. Dihydroxyacetone was produced through reversible isomerization of glyceraldehydes, while both dehydrated to form pyruvaldehyde [52]. Lactic acid was formed from pyruvaldehyde by benzilic acid rearrangement [53]. Hydroxymethylfurfural (HMF) was produced from dehydration of glucose [54, 55], and HMF hydrolysis produced levulinic acid and formic acid [56]. 1, 2, 4-benzenetriol was a decomposition product of HMF [57], while the 1, 2, 4-benzenetriol could continue to polymerize with HMF or other intermediates [58]. 
Polymerization and condensation reactions may be induced by intermolecular dehydration or aldol condensation, forming soluble polymers [59]. At the same time, the aromatization of polymers took place. Aromatic clusters may be produced by the intermolecular dehydration of aromatized molecules generated in the decomposition or dehydration. The presence of reactive aldehyde and alcohol groups in HMF suggested that this compound may easily polymerize to give long-chain molecules [60]. HMF was also in situ "polymerized" to polymeric carbonaceous materials [61].

The growth of nucleated carbon particles may follow the LaMer model [62]. When the concentration of soluble polymers reached the critical supersaturation point, nucleation occurred upon segregating the formed polymer that was phased out of the aqueous solution. Then the nuclei grew outwards by diffusion of solutes present in the solution towards their surface. These species were linked to the surface of microspheres via reactive oxygen-containing functional groups [41]. This process was called carbonization [31]. When the growth stopped, carbon materials formed from glucose had a condensed furanic system consisting of a hydrophobic core and a hydrophilic shell embedded with levulinic acid [30].

During HTC of cellulose, most cellulosic substrates underwent intramolecular condensation, dehydration, and decarboxylation reactions; and were converted to aromatic network structures. A very limited degree of hydrolysis and consequential individual glucose formation most likely took place simultaneously at the cellulose-water interface [41], and then reactions followed the same reaction pathway as glucose during the hydrothermal treatment [31].

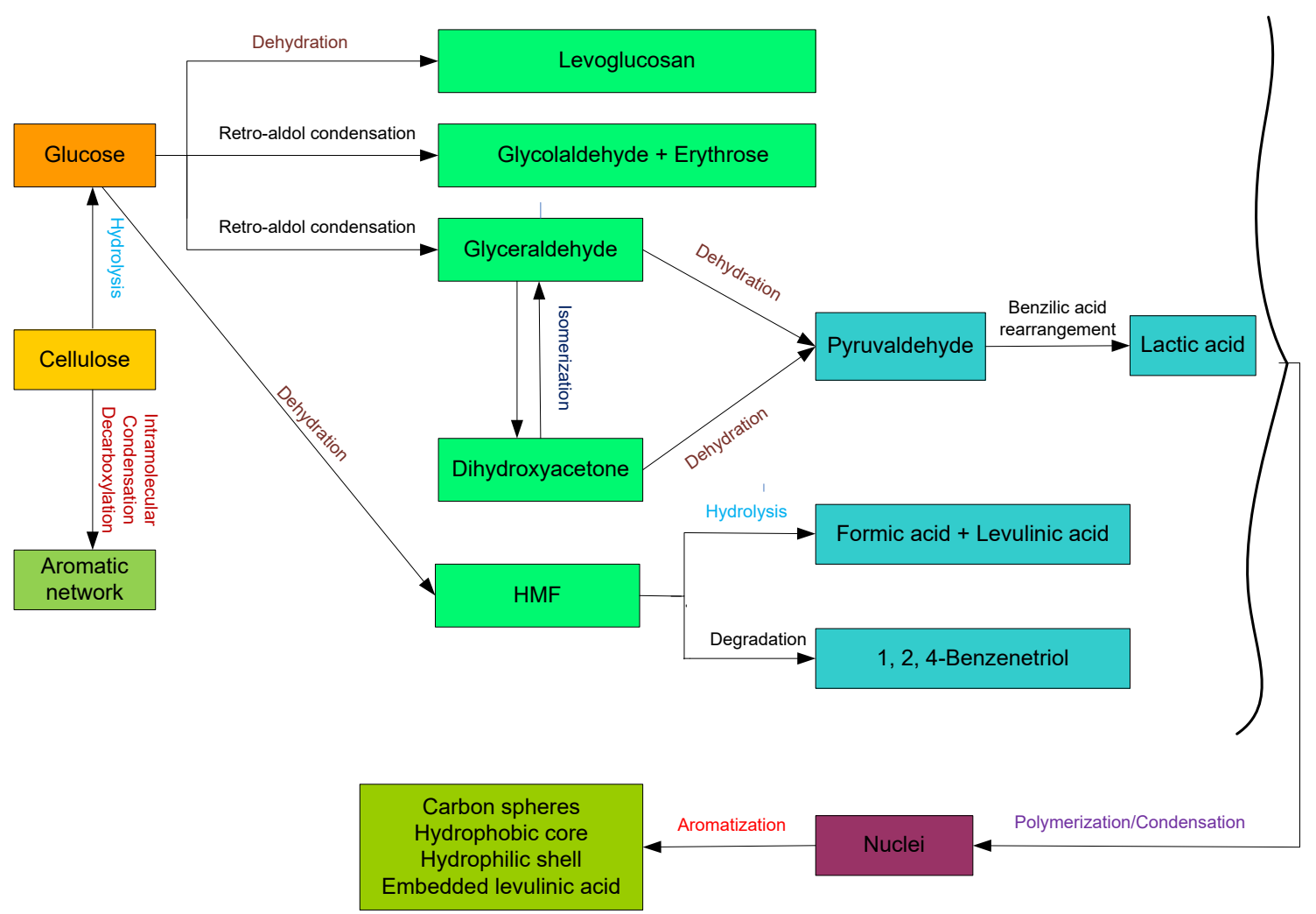

Figure 1. Schematic formation model for carbon spheres obtained from glucose and cellulose. 


\subsection{Applications of Hydrothermal Carbons}

Carbon materials derived from HTC processes have been used as absorbents for removal of $\mathrm{Cr}(\mathrm{VI})$ [63] and $\mathrm{Pb}(\mathrm{II})$ ions in water [10], and materials for lithium-ion batteries [64-67]. Due to the good dispersion and functional groups prepared by the HTC method, carbon spheres can be ideal catalyst supports [68,69].

One step HTC of the carbohydrate and metal solution can synthesize core-shell structure carbon spheres with hydrophobic metals as core and carbon as a shell. Silver cored carbon spheres were synthesized by $\mathrm{HTC}$ of $\mathrm{HAuCl}_{4}$ and glucose at $160-180{ }^{\circ} \mathrm{C}$ for 4-20 h [42]. Carbon spheres embedded with iron oxide nanoparticles, an excellent catalyst in the Fischer-Tropsch synthesis, was synthesized by HTC of glucose and iron nitrate [68]. During the hydrothermal treatment, iron nitrate was transformed to $\mathrm{FeOOH}$, which was further reduced to iron oxide by hydrogen during the carbonization process. Carbon spheres embedded with palladium nanoparticles were synthesized by HTC of furfural and palladium acetylacetonate. During the HTC process, the palladium acetylacetonate was reduced to elemental metallic palladium nanoparticles [70].

Metal oxides hollow spheres could be synthesized in a one-pot synthesis via HTC of carbohydrate and metal salt. During this HTC process, a hydrophilic shell with -OH or $\mathrm{C}=\mathrm{O}$ groups were prepared, and metal ions incorporated into the hydrophilic shell of carbon spheres. Hollow metal oxide spheres were obtained by calcining in air to remove encapsulated carbon. For example, the $\mathrm{TiO}_{2}$-hollow spheres were synthesized using carbon spheres as a template. Carbon spheres have -OH groups on their surface. The titanium source incorporated into the hydrophilic shell through the covalent -O-Ti bonding [71].

Inversely, carbon spheres with hollow structures can be made using metal as sacrificial templates. First, carbon spheres with the metal inside were made from hydrothermally treated carbohydrate and metal mixture. Then, the removal of metal resulted in hollow carbon spheres. For example, hollow carbon spheres were prepared from the HTC of glucose and $\mathrm{Zn}$ particles at $550^{\circ} \mathrm{C}$ for $8 \mathrm{~h}$. The products were washed with $\mathrm{HCl}$ to remove $\mathrm{Zn}$ and $\mathrm{ZnO}$ inside. The hollow carbon spheres were about 1-2 $\mu \mathrm{m}$ in diameter, and the surface area was $207 \mathrm{~m}^{2} / \mathrm{g}$ [72].

\section{CONCLUSIONS}

Hydrothermal carbonization (HTC) of carbohydrates is shown as a green and sustainable technology to synthesize carbon micro or nano spheres, which have a coreshell structure with a highly hydrophobic and aromatic nucleus, and a hydrophilic shell containing oxygenated functional groups. HTC reactions take place in pure water at mild conditions with cheap precursors. The size and the size distribution of carbon spheres could be modulated by synthesis conditions such as the treatment temperature, the reaction time, the concentration of starting materials, and the type of precursors. Detailed mechanisms involved in HTC of glucose include hydrolysis, dehydration, polymerization, condensation, and aromatization. Although the mechanism of glucose HTC is almost confirmed, the mechanism for real biomass conversion is still under investigation, because of unknown contributions from lignin, protein, and lipid. The model is needed to predict the particle size and the size distribution from parameters such as temperature, residue time, precursor concentration, different saccharides, and solution filing degree. The new applications of carbon spheres are still being investigated. 


\section{ACKNOWLEDGMENTS}

The authors are grateful for the support from the U.S. Department of Agriculture (USDA-NIFA Grant No. NCX-272-5-13-130-1).

\section{CONFLICTS OF INTEREST}

The authors declare that there is no conflict of interests regarding the publication of this paper.

\section{REFERENCES}

[1] Mi, C., and Chen, W. (2014). Highly nanoporous carbon microflakes from discarded dental impression materials. Materials Letters, 114, 129-131. DOI: 10.1016/j.matlet.2013.10.010

[2] White, R. J. (2015). Porous Carbon Materials from Sustainable Precursors, Royal Society of Chemistry

[3] Chen, J., Lang, Z., Xu, Q., Hu, B., Fu, J., Chen, Z., and Zhang, J. (2013). Facile Preparation of monodisperse carbon spheres: Template-free construction and their hydrogen storage properties. ACS Sustainable Chemistry \& Engineering, 1(8), 1063-1068. DOI: $10.1021 / \mathrm{sc} 400124 \mathrm{~b}$

[4] Zhang, K., Zhao, Q., Tao, Z., and Chen, J. (2013). Composite of sulfur impregnated in porous hollow carbon spheres as the cathode of Li-S batteries with high performance. Nano Research, 6(1), 38-46. DOI: 10.1007/s12274-012-0279-1

[5] Zhang, Z., Xiao, F., Xi, J., Sun, T., Xiao, S., Wang, H., Wang, S., and Liu, Y. (2014). Encapsulating Pd Nanoparticles in Double-Shelled Graphene@Carbon Hollow Spheres for Excellent Chemical Catalytic Property. Scientific reports, 4, Article number: 4053. DOI: 10.1038/srep04053

[6] Alazemi, A. A., Etacheri, V., Dysart, A., Stacke, L.-E., Pol, V., and Sadeghi, F. (2015). Ultrasmooth Submicron Carbon Spheres as Lubricant Additives for Friction and Wear Reduction. ACS Applied Materials \& Interfaces, 7(9), 55145521. DOI: 10.1021/acsami.5b00099

[7] Tien, B., Xu, M., and Liu, J. (2010). Synthesis and electrochemical characterization of carbon spheres as anode material for lithium-ion battery. Materials Letters, 64(13), 1465-1467. DOI: 10.1016/j.matlet.2010.03.061

[8] Tooming, T., Thomberg, T., Romann, T., Palm, R., Jänes, A., and Lust, E. (2013). Carbon materials for supercapacitor application by hydrothermal carbonization of D-glucose. IOP Conf. Ser.: Mater. Sci. Eng, 49, 012020. DOI: 10.1088/1757899X/49/1/012020

[9] Auer, E., Freund, A., Pietsch, J., and Tacke, T. (1998). Carbons as supports for industrial precious metal catalysts. Applied Catalysis A: General, 173(2), 259-271. DOI: 10.1016/S0926-860X(98)00184-7

[10] Chen, L.-F., Liang, H.-W., Lu, Y., Cui, C.-H., and Yu, S.-H. (2011). Synthesis of an Attapulgite Clay@Carbon Nanocomposite Adsorbent by a Hydrothermal 
Carbonization Process and Their Application in the Removal of Toxic Metal Ions from Water. Langmuir, 27(14), 8998-9004. DOI: 10.1021/la2017165

[11] Qian, H.-s., Han, F.-m., Zhang, B., Guo, Y.-c., Yue, J., and Peng, B.-x. (2004). Non-catalytic CVD preparation of carbon spheres with a specific size. Carbon, 42(4), 761-766. DOI: 10.1016/j.carbon.2004.01.004

[12] Serp, P., Feurer, R., Kalck, P., Kihn, Y., Faria, J., and Figueiredo, J. (2001). A chemical vapour deposition process for the production of carbon nanospheres. Carbon, 39(4), 621-626. DOI: 10.1016/S0008-6223(00)00324-9

[13] Joo, J. B., Kim, P., Kim, W., Kim, J., Kim, N. D., and Yi, J. (2008). Simple preparation of hollow carbon sphere via templating method. Current Applied Physics, 8(6), 814-817. DOI: 10.1016/j.cap.2007.04.038

[14] Ryoo, R., Joo, S. H., and Jun, S. (1999). Synthesis of Highly Ordered Carbon Molecular Sieves via Template-Mediated Structural Transformation. The Journal of Physical Chemistry B, 103(37), 7743-7746. DOI: 10.1021/jp991673a

[15] Jin, Y. Z., Gao, C., Hsu, W. K., Zhu, Y., Huczko, A., Bystrzejewski, M., Roe, M., Lee, C. Y., Acquah, S., and Kroto, H. (2005). Large-scale synthesis and characterization of carbon spheres prepared by direct pyrolysis of hydrocarbons. Carbon, 43(9), 1944-1953. DOI: 10.1016/j.carbon.2005.03.002

[16] Friedel, B., and Greulich-Weber, S. (2006). Preparation of Monodisperse, Submicrometer Carbon Spheres by Pyrolysis of Melamine-Formaldehyde Resin. small, 2(7), 859-863. DOI: 10.1002/smll.200500516

[17] Titirici, M.-M., and Antonietti, M. (2010). Chemistry and materials options of sustainable carbon materials made by hydrothermal carbonization. Chemical Society Reviews, 39(1), 103-116. DOI: 10.1039/B819318P

[18] Byrappa, K., and Adschiri, T. (2007). Hydrothermal technology for nanotechnology. Progress in Crystal Growth and Characterization of Materials, 53(2), 117-166. DOI: 10.1016/j.pcrysgrow.2007.04.001

[19] Yao, C., Shin, Y., Wang, L.-Q., Windisch, C. F., Samuels, W. D., Arey, B. W., Wang, C., Risen, W. M., and Exarhos, G. J. (2007). Hydrothermal Dehydration of Aqueous Fructose Solutions in a Closed System. The Journal of Physical Chemistry C, 111(42), 15141-15145. DOI: 10.1021/jp0741881

[20] Baccile, N., Laurent, G., Babonneau, F., Fayon, F., Titirici, M.-M., and Antonietti, M. (2009). Structural Characterization of Hydrothermal Carbon Spheres by Advanced Solid-State MAS 13C NMR Investigations. The Journal of Physical Chemistry C, 113(22), 9644-9654. DOI: 10.1021/jp901582x

[21] Krishnamurthy, G., and Namitha, R. (2013). Synthesis of structurally novel carbon micro/nanospheres by low temperature-hydrothermal process. Journal of the Chilean Chemical Society, 58(3), 1930-1933. DOI: 10.4067/S071797072013000300030

[22] Ramke, H.-G., Blöhse, D., Lehmann, H.-J., and Fettig, J. (2009). Hydrothermal carbonization of organic waste. In: Proc., Twelfth International Waste Management and Landfill Symposium, Sardinia, Italy.

[23] Bröll, D., Kaul, C., Kraemer, A., Krammer, P., Richter, T., Jung, M., Vogel, H., and Zehner, P. (1999). Chemistry in Supercritical Water. Angewandte Chemie International Edition, 38(20), 2998-3014. DOI: 10.1002/(SICI)15213773(19991018)38:20<2998::AID-ANIE2998>3.0.CO;2-L

[24] Libra, J. A., Ro, K. S., Kammann, C., Funke, A., Berge, N. D., Neubauer, Y., Titirici, M.-M., Fühner, C., Bens, O., and Kern, J. (2011). Hydrothermal 
carbonization of biomass residuals: a comparative review of the chemistry, processes and applications of wet and dry pyrolysis. Biofuels, 2(1), 71-106. DOI: 10.4155/BFS.10.81

[25] Titirici, M.-M. (2013). Sustainable carbon materials from hydrothermal processes, Wiley Online Library.

[26] Stranges, A. N. (1984). Friedrich Bergius and the Rise of the German Synthetic Fuel Industry. Isis, 75(4), 643-667. DOI: 10.2307/232411

[27] Titirici, M.-M., Antonietti, M., and Baccile, N. (2008). Hydrothermal carbon from biomass: a comparison of the local structure from poly-to monosaccharides and pentoses/hexoses. Green Chemistry, 10(11), 1204-1212. DOI: 10.1039/B807009A

[28] Wang, Q., Li, H., Chen, L., and Huang, X. (2001). Monodispersed hard carbon spherules with uniform nanopores. Carbon, 39(14), 2211-2214. DOI: 10.1016/S0008-6223(01)00040-9

[29] Qi, X., Lian, Y., Yan, L., and Smith, R. L. (2014). One-step preparation of carbonaceous solid acid catalysts by hydrothermal carbonization of glucose for cellulose hydrolysis. Catalysis Communications, 57, 50-54. DOI:

10.1016/j.catcom.2014.07.035

[30] Li, M., Li, W., and Liu, S. (2011). Hydrothermal synthesis, characterization, and $\mathrm{KOH}$ activation of carbon spheres from glucose. Carbohydrate Research, 346(8), 999-1004. DOI: 10.1016/j.carres.2011.03.020

[31] Sevilla, M., and Fuertes, A. B. (2009). Chemical and structural properties of carbonaceous products obtained by hydrothermal carbonization of saccharides. Chemistry-A European Journal, 15(16), 4195-4203. DOI:

10.1002/chem.200802097

[32] Mi, Y., Hu, W., Dan, Y., and Liu, Y. (2008). Synthesis of carbon micro-spheres by a glucose hydrothermal method. Materials Letters, 62(8), 1194-1196. DOI: 10.1016/j.matlet.2007.08.011

[33] Yi, Z., Liang, Y., Lei, X., Wang, C., and Sun, J. (2007). Low-temperature synthesis of nanosized disordered carbon spheres as an anode material for lithium ion batteries. Materials Letters, 61(19), 4199-4203. DOI: 10.1016/j.matlet.2007.01.054

[34] Zheng, M., Liu, Y., Xiao, Y., Zhu, Y., Guan, Q., Yuan, D., and Zhang, J. (2009). An easy catalyst-free hydrothermal method to prepare monodisperse carbon microspheres on a large scale. The Journal of Physical Chemistry C, 113(19), 8455-8459. DOI: 10.1021/jp811356a

[35] Funke, A., and Ziegler, F. (2010). Hydrothermal carbonization of biomass: a summary and discussion of chemical mechanisms for process engineering. Biofuels, Bioproducts and Biorefining, 4(2), 160-177. DOI: 10.1002/bbb.198

[36] Aydıncak, K., Yumak, T. r., Sinağ, A., and Esen, B. (2012). Synthesis and Characterization of Carbonaceous Materials from Saccharides (Glucose and Lactose) and Two Waste Biomasses by Hydrothermal Carbonization. Industrial \& Engineering Chemistry Research, 51(26), 9145-9152. DOI: 10.1021/ie301236h

[37] Robbiani, Z. (2013). Hydrothermal carbonization of biowaste/fecal sludge: Conception and construction of a HTC prototype research unit for developing countries. Master's Thesis, Swiss Federal Institute of Technology in Zurich (ETHZ).

[38] Demir-Cakan, R., Baccile, N., Antonietti, M., and Titirici, M.-M. (2009). Carboxylate-Rich Carbonaceous Materials via One-Step Hydrothermal 
Carbonization of Glucose in the Presence of Acrylic Acid. Chemistry of materials, 21(3), 484-490. DOI: 10.1021/cm802141h

[39] Demir-Cakan, R., Hu, Y.-S., Antonietti, M., Maier, J., and Titirici, M.-M. (2008). Facile One-Pot Synthesis of Mesoporous SnO2 Microspheres via Nanoparticles Assembly and Lithium Storage Properties. Chemistry of materials, 20(4), 1227 1229. DOI: $10.1021 / \mathrm{cm} 7031288$

[40] Yu, L., Falco, C., Weber, J., White, R. J., Howe, J. Y., and Titirici, M.-M. (2012). Carbohydrate-Derived Hydrothermal Carbons: A Thorough Characterization Study. Langmuir, 28(33), 12373-12383. DOI: 10.1021/la3024277

[41] Falco, C., Baccile, N., and Titirici, M.-M. (2011). Morphological and structural differences between glucose, cellulose and lignocellulosic biomass derived hydrothermal carbons. Green Chemistry, 13(11), 3273-3281. DOI: $10.1039 / \mathrm{C} 1 \mathrm{GC} 15742 \mathrm{~F}$

[42] Sun, X., and Li, Y. (2004). Colloidal Carbon Spheres and Their Core/Shell Structures with Noble-Metal Nanoparticles. Angewandte Chemie International Edition, 43(5), 597-601. DOI: 10.1002/anie.200352386

[43] Yin, S., and Tan, Z. (2012). Hydrothermal liquefaction of cellulose to bio-oil under acidic, neutral and alkaline conditions. Applied Energy, 92, 234-239. DOI: 10.1016/j.apenergy.2011.10.041

[44] Berge, N. D., Ro, K. S., Mao, J., Flora, J. R. V., Chappell, M. A., and Bae, S. (2011). Hydrothermal Carbonization of Municipal Waste Streams. Environmental Science \& Technology, 45(13), 5696-5703. DOI: 10.1021/es2004528

[45] Sevilla, M., Maciá-Agulló, J. A., and Fuertes, A. B. (2011). Hydrothermal carbonization of biomass as a route for the sequestration of CO2: Chemical and structural properties of the carbonized products. Biomass and Bioenergy, 35(7), 3152-3159. DOI: 10.1016/j.biombioe.2011.04.032

[46] Chheda, J. N., Román-Leshkov, Y., and Dumesic, J. A. (2007). Production of 5hydroxymethylfurfural and furfural by dehydration of biomass-derived mono-and poly-saccharides. Green Chemistry, 9(4), 342-350. DOI: 10.1039/B611568C

[47] Xiang, Q., Lee, Y., and Torget, R. (2004). Kinetics of glucose decomposition during dilute-acid hydrolysis of lignocellulosic biomass. Applied Biochemistry and Biotechnology, 115(1-3), 1127-1138. DOI: 10.1385/abab:115:1-3:1127

[48] Antal, M. J., Mok, W. S., and Richards, G. N. (1990). Mechanism of formation of 5-(hydroxymethyl)-2-furaldehyde from D-fructose and sucrose. Carbohydrate Research, 199(1), 91-109. DOI: 10.1016/0008-6215(90)84096-D

[49] Peterson, A. A., Vogel, F., Lachance, R. P., Fröling, M., Antal Jr, M. J., and Tester, J. W. (2008). Thermochemical biofuel production in hydrothermal media: A review of sub-and supercritical water technologies. Energy \& Environmental Science, 1(1), 32-65. DOI: 10.1039/B810100K

[50] Sasaki, M., Goto, K., Tajima, K., Adschiri, T., and Arai, K. (2002). Rapid and selective retro-aldol condensation of glucose to glycolaldehyde in supercritical water. Green Chemistry, 4(3), 285-287. DOI: 10.1039/b203968k

[51] Srokol, Z., Bouche, A.-G., van Estrik, A., Strik, R. C., Maschmeyer, T., and Peters, J. A. (2004). Hydrothermal upgrading of biomass to biofuel; studies on some monosaccharide model compounds. Carbohydrate Research, 339(10), 1717-1726. DOI: 10.1016/j.carres.2004.04.018

[52] Kabyemela, B. M., Adschiri, T., Malaluan, R., and Arai, K. (1997). Degradation Kinetics of Dihydroxyacetone and Glyceraldehyde in Subcritical and Supercritical 
Water. Industrial \& Engineering Chemistry Research, 36(6), 2025-2030. DOI: 10.1021/ie960747r

[53] Chen, L. (2011). Conversion of Glycerol to Lactic Acid under Low Corrosive Conditions with Homogeneous and Heterogeneous Catalysts. Master's Thesis, University of Tennessee

[54] Asghari, F. S., and Yoshida, H. (2007). Kinetics of the Decomposition of Fructose Catalyzed by Hydrochloric Acid in Subcritical Water: Formation of 5Hydroxymethylfurfural, Levulinic, and Formic Acids. Industrial \& Engineering Chemistry Research, 46(23), 7703-7710. DOI: 10.1021/ie061673e

[55] Möller, M., Nilges, P., Harnisch, F., and Schröder, U. (2011). Subcritical Water as Reaction Environment: Fundamentals of Hydrothermal Biomass Transformation. ChemSusChem, 4(5), 566-579. DOI: 10.1002/cssc.201000341

[56] Weingarten, R., Conner, W. C., and Huber, G. W. (2012). Production of levulinic acid from cellulose by hydrothermal decomposition combined with aqueous phase dehydration with a solid acid catalyst. Energy \& Environmental Science, 5(6), 7559-7574. DOI: 10.1039/c2ee21593d

[57] Luijkx, G. C. A., van Rantwijk, F., and van Bekkum, H. (1993). Hydrothermal formation of 1,2,4-benzenetriol from 5-hydroxymethyl-2-furaldehyde and dfructose. Carbohydrate Research, 242(0), 131-139. DOI: 10.1016/00086215(93)80027-C

[58] Chuntanapum, A., and Matsumura, Y. (2009). Formation of Tarry Material from 5-HMF in Subcritical and Supercritical Water. Industrial \& Engineering Chemistry Research, 48(22), 9837-9846. DOI: 10.1021/ie900423g

[59] Salak Asghari, F., and Yoshida, H. (2006). Acid-Catalyzed Production of 5Hydroxymethyl Furfural from d-Fructose in Subcritical Water. Industrial \& Engineering Chemistry Research, 45(7), 2163-2173. DOI: 10.1021/ie051088y

[60] Scallet, B. L., and Gardner, J. H. (1945). Formation of 5-Hydroxymethylfurfural from D-Glucose in Aqueous Solution. Journal of the American Chemical Society, 67(11), 1934-1935. DOI: 10.1021/ja01227a017

[61] Patil, S. K., and Lund, C. R. (2011). Formation and growth of humins via aldol addition and condensation during acid-catalyzed conversion of 5hydroxymethylfurfural. Energy \& Fuels, 25(10), 4745-4755. DOI: 10.1021/ef2010157

[62] LaMer, V. K., and Dinegar, R. H. (1950). Theory, production and mechanism of formation of monodispersed hydrosols. Journal of the American Chemical Society, 72(11), 4847-4854. DOI: 10.1021/ja01167a001

[63] Li, T., Shen, J., Huang, S., Li, N., and Ye, M. (2014). Hydrothermal carbonization synthesis of a novel montmorillonite supported carbon nanosphere adsorbent for removal of Cr (VI) from waste water. Applied Clay Science, 93-94, 48-55. DOI: 10.1016/j.clay.2014.02.015

[64] Yang, R., Zhao, W., Zheng, J., Zhang, X., and Li, X. (2010). One-Step Synthesis of Carbon-Coated Tin Dioxide Nanoparticles for High Lithium Storage. The Journal of Physical Chemistry C, 114(47), 20272-20276. DOI:

10.1021/jp107396a

[65] Zhao, N., Wu, S., He, C., Wang, Z., Shi, C., Liu, E., and Li, J. (2013). One-pot synthesis of uniform $\mathrm{Fe} 3 \mathrm{O} 4$ nanocrystals encapsulated in interconnected carbon nanospheres for superior lithium storage capability. Carbon, 57, 130-138. DOI: 10.1016/j.carbon.2013.01.056 
[66] Lou, X. W., Chen, J. S., Chen, P., and Archer, L. A. (2009). One-Pot Synthesis of Carbon-Coated SnO2 Nanocolloids with Improved Reversible Lithium Storage Properties. Chemistry of materials, 21(13), 2868-2874. DOI: 10.1021/cm900613d

[67] Chen, J. S., Zhang, Y., and Lou, X. W. (2011). One-Pot Synthesis of Uniform Fe3O4 Nanospheres with Carbon Matrix Support for Improved Lithium Storage Capabilities. ACS Applied Materials \& Interfaces, 3(9), 3276-3279. DOI: 10.1021/am201079z

[68] Yu, G., Sun, B., Pei, Y., Xie, S., Yan, S., Qiao, M., Fan, K., Zhang, X., and Zong, B. (2009). FexOy@C Spheres as an Excellent Catalyst for Fischer-Tropsch Synthesis. Journal of the American Chemical Society, 132(3), 935-937. DOI: 10.1021/ja906370b

[69] Cheng, J., Wang, Y., Teng, C., Shang, Y., Ren, L., and Jiang, B. (2014). Preparation and characterization of monodisperse, micrometer-sized, hierarchically porous carbon spheres as catalyst support. Chemical Engineering Journal, 242, 285-293. DOI: 10.1016/j.cej.2013.12.089

[70] Makowski, P., Cakan, R. D., Antonietti, M., Goettmann, F., and Titirici, M.-M. (2008). Selective partial hydrogenation of hydroxy aromatic derivatives with palladium nanoparticles supported on hydrophilic carbon. Chemical Communications(8), 999-1001. DOI: 10.1039/B717928F

[71] Shen, W., Zhu, Y., Dong, X., Gu, J., and Shi, J. (2005). A new strategy to synthesize TiO2-hollow spheres using carbon spheres as template. ChemInform, 34(40), no. DOI: 10.1002/chin.200540213

[72] Wang, F.-L., Pang, L.-L., Jiang, Y.-Y., Chen, B., Lin, D., Lun, N., Zhu, H.-L., Liu, R., Meng, X.-L., and Wang, Y. (2009). Simple synthesis of hollow carbon spheres from glucose. Materials Letters, 63(29), 2564-2566. DOI:

10.1016/j.matlet.2009.09.008

Article copyright: (C) 2015 Rui Li and Abolghasem Shahbazi. This is an open access article distributed under the terms of the Creative Commons Attribution 4.0 International License, which permits unrestricted use and distribution provided the original author and source are credited. 
To cite this article:

Li, R. and Shahbazi, A. (2015). "A Review of Hydrothermal Carbonization of Carbohydrates for Carbon Spheres Preparation." Trends in Renewable Energy, 1(1), 4356. http://dx.doi.org/10.17737/tre.2015.1.1.009 